\title{
Effect of age on the development of chemotherapy-associated liver injury in colorectal cancer liver metastasis
}

\author{
TAIICHI WAKIYA ${ }^{1}$, DAISUKE KUDO ${ }^{1}$, KEINOSUKE ISHIDO ${ }^{1}$, NORIHISA KIMURA ${ }^{1}$, \\ YUTA YAKOSHI $^{1}$, YOSHIKAZU TOYOKI ${ }^{1}$, HIROSHI KIJIMA ${ }^{2}$ and KENICHI HAKAMADA ${ }^{1}$ \\ Departments of ${ }^{1}$ Gastroenterological Surgery and ${ }^{2}$ Pathology and Bioscience, Hirosaki \\ University Graduate School of Medicine, Hirosaki, Aomori 036-8562, Japan
}

Received March 13, 2017; Accepted May 10, 2017

DOI: $10.3892 / \mathrm{mco} .2017 .1314$

\begin{abstract}
With the prolongation of the mean lifespan, the number of elderly individuals undergoing liver resection for colorectal cancer liver metastasis (CRLM) following chemotherapy has increased. However, the effect of age on the development of chemotherapy-associated liver injury (CALI) in CRLM remains unclear. The aim of the present study was to elucidate the effect of age on the development of CALI in CRLM. A total of 64 patients undergoing liver resection for CRLM following oxaliplatin-based chemotherapy (OBC) were investigated. The patients were divided into three groups (group A: $<65$ years, group B: $65-74$ years and group C: $>75$ years) according to age at surgery, and the development rate of CALI was compared between the groups. The patients underwent pathological assessments to determine the degree of histopathological injury of the non-cancerous liver parenchyma. Group A included 37 cases, group B 17 cases and group C 10 cases. There were no significant differences among the groups regarding the number of $\mathrm{OBC}$ cycles and duration of OBC cessation. Sinusoidal injury was observed in 27.0, 29.4 and $30.0 \%$ of the cases in groups A, B and C, respectively; the differences were not statistically significant $(\mathrm{P}=0.479)$. Steatohepatitis was observed in 35.1, 35.3 and $40.0 \%$ of the cases in groups $\mathrm{A}, \mathrm{B}$ and $\mathrm{C}$, respectively; the differences were not statistically significant $(\mathrm{P}=0.958)$. There was no significant correlation between age and sinusoidal
\end{abstract}

Correspondence to: Professor Kenichi Hakamada, Department of Gastroenterological Surgery, Hirosaki University Graduate School of Medicine, 5 Zaifu-cho, Hirosaki, Aomori 036-8562, Japan E-mail: hakamada@hirosaki-u.ac.jp

Abbreviations: BMI, body mass index; CALI, chemotherapyassociated liver injury; CapeOX, capecitabine+ oxaliplatin; CRLM, colorectal liver metastasis; FOLFOX, 5 fluorouracil + leucovorin + oxaliplatin; NAFLD, non-alcoholic fatty liver disease; OBC, oxaliplatin-based chemotherapy; SH, steatohepatitis; SI, sinusoidal injury; SOX, S-1 + oxaliplatin

Key words: colorectal liver metastasis, chemotherapy, drug-induced liver injury, risk factor, aging pathological score $(\mathrm{r}=-0.102, \mathrm{P}=0.423)$ or non-alcoholic fatty liver disease activity score $(r \leq 0.001, P=0.997)$. Therefore, the development of CALI following OBC treatment in CRLM was not found to differ by age.

\section{Introduction}

Liver resection with systemic chemotherapy is the only treatment offering the possibility of long-term survival in patients with colorectal cancer liver metastasis (CRLM) (1-4). However, systemic chemotherapy for CRLM has been shown to cause chemotherapy-associated liver injury (CALI), including sinusoidal injury (SI) and steatohepatitis (SH), which may increase the morbidity and mortality following major liver resection (5-10). Therefore, it is crucial to prevent the development of CALI and identify the associated risk factors. With the prolongation of the average life span, the number of elderly individuals undergoing liver resection for CRLM following chemotherapy has increased. However, the effect of age on the development of CALI in CRLM remains unclear. The aim of the present study was to elucidate the effects of age on the development of CALI in CRLM.

\section{Patients and methods}

Patients. Patients undergoing liver resection for CRLM following chemotherapy between April 2009 and March 2015 were considered for inclusion in this study. A total of 64 patients met the inclusion criteria and comprised the study population. The inclusion criteria were as follows: First liver resection, administration of oxaliplatin-based chemotherapy (OBC) within 4 months prior to liver resection, absence of preoperative jaundice, and availability of formalin-fixed, paraffin-embedded liver parenchymal tissue from the non-cancerous parenchyma for pathological analysis. The study protocol was approved by the Institutional Review Committee of the Hirosaki University Graduate School of Medicine (Hirosaki, Japan).

Pathological assessment. All histological slides that were originally prepared from formalin-fixed and paraffin-embedded tissues were reviewed. The morphological analyses were performed using slides stained with hematoxylin and eosin. 
The slides were examined by 3 pathologists who were blinded to the clinical data. SI was graded according to the sinusoidal pathological score reported by Rubbia-Brandt et al (7). SI was classified as follows: 0, absent; 1, mild (centrilobular involvement limited to one-third of the lobule); 2, moderate (centrilobular involvement extending to two-thirds of the lobule); and 3, severe (complete lobular involvement). SH was graded according to the non-alcoholic fatty liver disease (NAFLD) activity score, as defined by Kleiner et al, based on steatosis, lobular inflammation and ballooning (11). Sinusoidal pathological scores of 0 and 1 were diagnosed as non-SI, and an NAFLD score of $<3$ was diagnosed as non-SH.

Comparison of perioperative factors. The 64 patients were divided into three groups (group A: $<65$ years, group B: 65-74 years and group $\mathrm{C}$ : $>75$ years) according to age at surgery. The medical records of all the patients were retrospectively reviewed and the development rate of CALI was compared between the groups. In addition, the association between the pathological score (SI and $\mathrm{SH}$ ) and age at surgery was analyzed.

Preoperative chemotherapy. The systemic chemotherapy regimens consisted of three patterns: 5-fluorouracil + leucovorin + oxaliplatin (FOLFOX), capecitabine + oxaliplatin (CapeOX) and S-1 + oxaliplatin (SOX). In 52 patients, cytotoxic chemotherapy was combined with molecularly targeted therapy. In the present analysis, regimens of molecularly targeted therapy + FOLFOX, CapeOX or SOX were referred to as FOLFOX, CapeOX or SOX regimens, respectively. Chemotherapy regimens, including dose reduction, were selected at the discretion of the treating physician.

Statistical analysis. Continuous variables were expressed as median (range) and analyzed using non-parametric methods for non-normally distributed data (Mann-Whitney U-test). Categorical variables were reported as number (percentage) and analyzed using the Chi-squared test or Fisher's exact test, as appropriate.

For comparing the three groups, the Kruskal-Wallis test and Bonferroni correction were used. Univariate and multivariate analyses were performed using logistic regression analysis to determine the risk factors associated with CALI. In analyses of the preoperative parameters, the median value was used to determine the cut-off level. Any variable with $\mathrm{P}<0.1$ on univariate analysis using the abovementioned test was considered to be a candidate for the multivariate analysis.

Correlations between the pathological score and age at surgery were assessed using Spearman's correlation. A correlation was considered statistically significant when the correlation coefficient $(r)$ was $>0.3$. A difference was considered to be significant when the P-value was $<0.05$. The statistical analysis was performed using the Predictive Analytics Software Package, version 18.0 (SPSS Inc., Chicago, IL, USA).

\section{Results}

Patient characteristics. The characteristics of the patients are summarized in Table I. There were 44 male and 20 female
Table I. Patient characteristics.

\begin{tabular}{lc}
\hline Characteristics & No. $(\%)$ \\
\hline Gender (male/female) & $44 / 20(68.8 / 31.3)$ \\
Age, years [median (range)] & $62(42-81)$ \\
Body mass index, $\mathrm{kg} / \mathrm{m}^{2}$ [median (range)] & $21.6(17.3-37.9)$ \\
Body surface area, $\mathrm{m}^{2}$ [median (range)] & $1.63(1.27-2.10)$ \\
Primary lesion & \\
Colon/rectum & $27 / 37(42.2 / 57.8)$ \\
Chemotherapeutic regimen & \\
FOLFOX & $28(43.8)$ \\
CapeOX & $29(45.3)$ \\
SOX & $7(10.9)$ \\
Molecularly targeted therapy & $52(81.3)$ \\
Bevacizumab & $47(73.4)$ \\
No. of OBC cycles [median (range)] & $5(2-22)$ \\
Duration of OBC cessation, & $7(3-16)$ \\
weeks [median (range)] & \\
Pathological response & \\
1a & $19(29.7)$ \\
1b & $26(35.9)$ \\
2 & $16(25.0)$ \\
3 & $3(4.7)$ \\
Ninusoidal pathological score $\geq 2$ & \\
NAFD activity score $\geq 3$ & \\
\hline
\end{tabular}

OBC, oxaliplatin-based chemotherapy; FOLFOX, 5-fluorouracil + leucovorin + oxaliplatin; CapeOX, capecitabine + oxaliplatin; SOX, S-1 + oxaliplatin; NAFLD, nonalcoholic fatty liver disease.

subjects, with a median age of 62 years (range, 42-81 years). The primary lesions were colon cancer in 27 patients and rectal cancer in 37 patients. The OBC regimens were FOLFOX, CapeOX and SOX. Multiple regimens were required in 16 patients, 4 of whom $(4 / 64,6.25 \%)$ had a history of irinotecan-based chemotherapy. Molecularly targeted therapy was administered to the majority of the patients (52/64), 47 of whom received bevacizumab. The median duration of $\mathrm{OBC}$ cessation was 7 weeks. Approximately 28 and $36 \%$ of the cases in each group had SI and $\mathrm{SH}$, respectively.

Comparison of preoperative characteristics by age at surgery. Group A included 37 cases, group B 17 cases and group C 10 cases. A comparison of the preoperative characteristics prior to liver resection is shown in Table II. The body surface area decreased with age; however, the difference was not statistically significant. There were no significant differences among the groups regarding the number of $\mathrm{OBC}$ cycles or the duration of $\mathrm{OBC}$ cessation.

Comparison of preoperative blood tests by age at surgery. Table III shows a comparison of the preoperative blood test results prior to liver resection. The prothrombin time-international normalized ratio, total bilirubin, aspartate aminotransferase and alanine aminotransferase levels 
Table II. Comparison of preoperative characteristics according to age at surgery.

\begin{tabular}{|c|c|c|c|c|}
\hline Characteristics & $\begin{array}{c}\text { Group A } \\
(<65 \text { years })\end{array}$ & $\begin{array}{c}\text { Group B } \\
(65-74 \text { years })\end{array}$ & $\begin{array}{c}\text { Group C } \\
(>75 \text { years })\end{array}$ & P-value \\
\hline Patient total & 37 & 17 & 10 & \\
\hline Gender (male/female) & $24 / 13$ & $12 / 5$ & $8 / 2$ & 0.65 \\
\hline Median age, years & 57.0 & $69.0^{\mathrm{a}}$ & $78.0^{\mathrm{a}}$ & $<0.01$ \\
\hline Median body mass index, $\mathrm{kg} / \mathrm{m}^{2}$ & 21.3 & 21.8 & 21.6 & 0.82 \\
\hline Median body surface area, $\mathrm{m}^{2}$ & 1.69 & 1.61 & 1.59 & 0.31 \\
\hline Median no. of OBC cycles & 5.0 & 5.0 & 6.5 & 0.44 \\
\hline Median duration of OBC cessation, weeks & 7.0 & 7.0 & 7.0 & 0.57 \\
\hline Molecularly targeted therapy (+) & $31(83.8)$ & $12(70.6)$ & $9(90.0)$ & 0.56 \\
\hline Bevacizumab (+) & $30(81.1)$ & $9(52.9)$ & $8(80.0)$ & 0.26 \\
\hline Antiplatelet therapy (+) & $4(10.8)$ & $2(11.8)$ & $3(30.0)$ & 0.14 \\
\hline
\end{tabular}

${ }^{\mathrm{a}} \mathrm{P}<0.01$ vs. the $<65$ group. OBC, oxaliplatin-based chemotherapy.

Table III. Comparison of preoperative blood test results according to age at surgery.

\begin{tabular}{|c|c|c|c|c|}
\hline Variables (median) & $\begin{array}{c}\text { Group A } \\
(<65 \text { years })\end{array}$ & $\begin{array}{c}\text { Group B } \\
(65-74 \text { years })\end{array}$ & $\begin{array}{c}\text { Group C } \\
(>75 \text { years })\end{array}$ & P-value \\
\hline Patient total & 37 & 17 & 10 & \\
\hline Patient total & 37 & 17 & 10 & \\
\hline Plt, $10^{4} / \mu 1$ & 19.5 & 18.4 & 16.1 & 0.45 \\
\hline PT-INR & 1.02 & 1.02 & 1.03 & 0.73 \\
\hline ALB, g/dl & 4.3 & 4.1 & $3.7^{\mathrm{a}}$ & $<0.01$ \\
\hline AST, U/l & 25.0 & 26.0 & 22.5 & 0.67 \\
\hline ALT, U/1 & 25.0 & 21.0 & 18.5 & 0.19 \\
\hline T-Bil, mg/dl & 0.6 & 0.6 & 0.5 & 0.18 \\
\hline ICG-R15, \% & 13.0 & 11.0 & 13.0 & 0.72 \\
\hline APRI score & 0.36 & 0.43 & 0.40 & 0.69 \\
\hline FIB-4 score ${ }^{b}$ & 1.58 & 2.23 & $2.42^{\mathrm{a}}$ & $<0.01$ \\
\hline
\end{tabular}

${ }^{\mathrm{a}} \mathrm{P}<0.01$ vs. the $<65$ group. ${ }^{\mathrm{b}} \mathrm{Age}$ (years) x AST (U/l)/[Plt (10\%/10) x (ALT (U/1) ${ }^{1 / 2}$. FIB, fibrosis; Plt, platelet; PT-INR, prothrombin time-international normalized ratio; ALB, albumin; AST, aspartate aminotransferase; ALT, alanine aminotransferase; T-Bil, total bilirubin; ICG-R15, indocyanine green retention rate at $15 \mathrm{~min}$; APRI, aspartate aminotransferase to platelet ratio index.

were not significantly different among the three age groups. Furthermore, the indocyanine green retention rate at $15 \mathrm{~min}$ did not exhibit any consistent trends with aging.

Comparison of pathological score by age at surgery. A comparison of the pathological score of liver parenchymal tissue from non-cancerous regions is shown in Fig. 1. SI was observed in 10, 5 and 3 patients from groups $A, B$ and $C$, respectively, which was not significantly different $(\mathrm{P}=0.479)$. SH was observed in 13, 6 and 4 patients of groups A, B and C, respectively, which was also not significantly different $(\mathrm{P}=0.958)$.

Correlation between age at surgery and pathological scores. There was no significant correlation between age and the sinusoidal pathological score $(\mathrm{r}=-0.102, \mathrm{P}=0.423)$ or non-alcoholic fatty liver disease activity score $(r=<0.001$, $\mathrm{P}=0.997)$.

Risk factors for SI. Based on the results of the univariate analysis, a high body mass index (BMI), large number of OBC cycles, bevacizumab-containing regimens and long duration of OBC cessation were considered candidates for the multivariate analysis. The multivariate analysis revealed that a large number of OBC cycles was an independent risk factor for SI (Table IV).

Risk factors for $\mathrm{SH}$. Based on the results of the univariate analysis, a high BMI and a large number of OBC cycles were considered candidates for the multivariate analysis. The multivariate analysis did not identify any variables as independent risk factors for $\mathrm{SH}$ (Table IV). 
Table IV. Multivariate analysis of the risk factors for CALI.

\begin{tabular}{|c|c|c|c|c|}
\hline \multirow[b]{2}{*}{ Variables } & \multirow{2}{*}{$\begin{array}{c}\begin{array}{c}\text { Univariate } \\
\text { analysis }\end{array} \\
\text { P-value }\end{array}$} & \multicolumn{3}{|c|}{ Multivariate analysis } \\
\hline & & Odds ratio & $95 \% \mathrm{CI}$ & P-value \\
\hline \multicolumn{5}{|l|}{ Risk factors for SI } \\
\hline $\mathrm{BMI}>21.6 \mathrm{~kg} / \mathrm{m}^{2}$ & 0.095 & 1.819 & $0.506-6.543$ & 0.36 \\
\hline No. of OBC cycles $>5$ & $<0.01$ & 3.725 & $1.020-13.601$ & 0.047 \\
\hline Duration of OBC cessation $>7$ weeks & 0.09 & 0.227 & $0.049-1.050$ & 0.06 \\
\hline Bevacizumab-containing regimens & 0.046 & 0.327 & $0.083-1.291$ & 0.11 \\
\hline \multicolumn{5}{|l|}{ Risk factors for $\mathrm{SH}$} \\
\hline $\mathrm{BMI}>21.6 \mathrm{~kg} / \mathrm{m}^{2}$ & 0.07 & 0.488 & $0.160-1.486$ & 0.21 \\
\hline No. of OBC cycles $>5$ & 0.02 & 3.045 & $0.962-9.638$ & 0.06 \\
\hline
\end{tabular}

CALI, chemotherapy-associated liver injury; SI, sinusoidal injury; BMI, body mass index; OBC, oxaliplatin-based chemotherapy; SH, steatohepatitis.
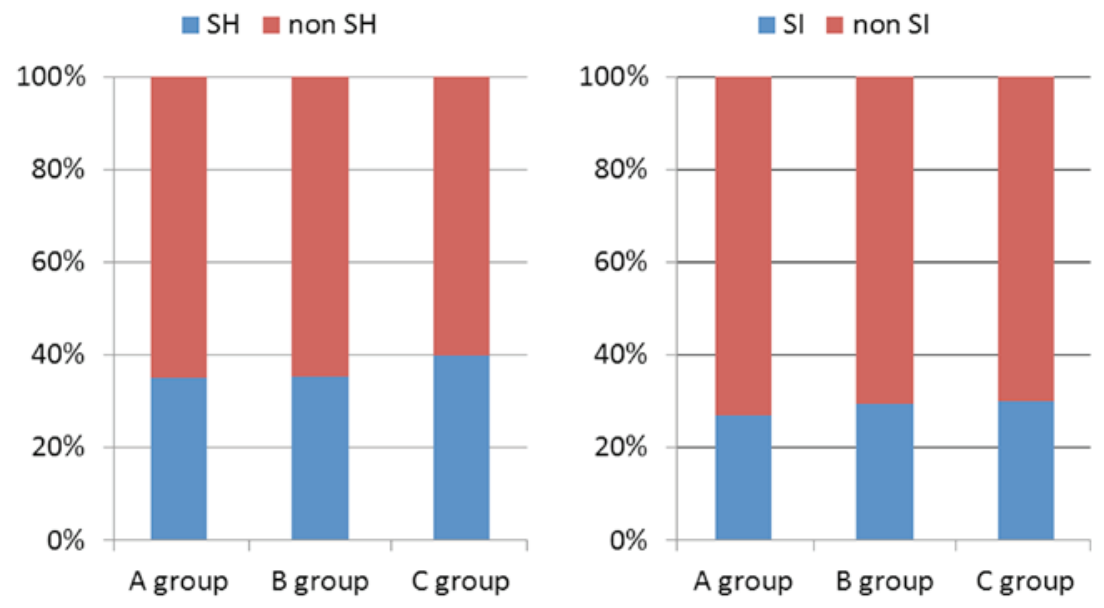

Figure 1. Frequency of chemotherapy-associated liver injury in patients with liver metastasis from colorectal cancer according to age at surgery. SI, sinusoidal injury; $\mathrm{SH}$, steatohepatitis.

\section{Discussion}

Systemic chemotherapy for metastatic colorectal cancer may cause non-specific as well as specific damage to the non-cancerous liver parenchyma. OBC plays a central role in the treatment of patients with CRLM and may induce SI, which may increase the risk of liver resection for CRLM (5,6,9,12-14). Although there is no established guideline to prevent the development of chemotherapy-associated SI, the following factors have been identified as risk factors for SI: Female gender, a high number of chemotherapy cycles, and a short interval between cessation of chemotherapy and liver resection $(5,15)$. However, the effect of age on the development of chemotherapy-associated SI remains unclear.

In previously published reports comparing two groups according to the histopathological assessment of SI, the development of chemotherapy-associated SI did not differ by age $(5,14,16,17)$. However, it is difficult to conclude that these findings are sufficient, as those studies did not focus on age. Furthermore, in a previous large study on the safety of $\mathrm{OBC}$ in elderly patients with colorectal cancer, CALI was not sufficiently investigated (18). Understandably, the pathological evaluation of CALI is likely difficult in such a large study. Therefore, the aim of the present study was to specifically focus on the age of the patients and pathological evaluation of SI.

There was no significant difference in the pathological score of the liver parenchymal tissue of the non-cancerous region among the groups. Furthermore, there was no strong correlation between age at surgery and the pathological score of SI or SH. These results suggested that the rate of development of severe CALI, which increases the morbidity and mortality following hepatectomy after OBC in CRLM, does not differ markedly by age. Unfortunately, detailed information on the relative dose intensity was not available, as nearly all cases were introduced from other institutions. However, a previous pooled analysis of elderly patients with colorectal cancer suggested that increasing age did not adversely affect drug delivery (18). Therefore, the effect of age alone on severe 
CALI appears to be limited, provided that chemotherapy is appropriately conducted.

Although the present study provides insight into the management of CRLM among elderly patients in routine clinical practice, there were certain limitations, including the small sample size and retrospective design. In addition, the elderly patients included in this study were operable patients in good physical condition with few complications. Thus, patients who do not undergo surgery must also be evaluated to confirm our findings regarding the effect of age on the development of CALI in CRLM. However, in such cases, a liver biopsy would be required for the pathological examination of CALI, but this may not be possible for all cases due to ethical considerations.

In conclusions, the development of CALI following OBC in CRLM did not differ by age. The effect of increasing age on the development of severe CALI appears to be limited, provided that chemotherapy is appropriately conducted.

\section{References}

1. Bismuth H, Adam R, Lévi F, Farabos C, Waechter F, Castaing D, Majno $\mathrm{P}$ and Engerran L: Resection of nonresectable liver metastases from colorectal cancer after neoadjuvant chemotherapy. Ann Surg 224: 509-522, 1996.

2. Adam R, Delvart V, Pascal G, Valeanu A, Castaing D, Azoulay D, Giacchetti S, Paule B, Kunstlinger F, Ghémard O, et al: Rescue surgery for unresectable colorectal liver metastases downstaged by chemotherapy: A model to predict long-term survival. Ann Surg 240: 644-658, 2004.

3. Leonard GD, Brenner B and Kemeny NE: Neoadjuvant chemotherapy before liver resection for patients with unresectable liver metastases from colorectal carcinoma. J Clin Oncol 23 2038-2048, 2005.

4. Nordlinger B, Sorbye H, Glimelius B, Poston GJ, Schlag PM, Rougier P, Bechstein WO, Primrose JN, Walpole ET, Finch-Jones M, et al: Perioperative chemotherapy with FOLFOX4 and surgery versus surgery alone for resectable liver metastases from colorectal cancer (EORTC Intergroup trial 40983): A randomised controlled trial. Lancet 371: 1007-1016, 2008.

5. Nakano H, Oussoultzoglou E, Rosso E, Casnedi S, Chenard-Neu MP, Dufour P, Bachellier P and Jaeck D: Sinusoida injury increases morbidity after major hepatectomy in patients with colorectal liver metastases receiving preoperative chemotherapy. Ann Surg 247: 118-124, 2008.

6. Vauthey JN, Pawlik TM, Ribero D, Wu TT, Zorzi D, Hoff PM, Xiong HQ, Eng C, Lauwers GY, Mino-Kenudson M, et al: Chemotherapy regimen predicts steatohepatitis and an increase in 90-day mortality after surgery for hepatic colorectal metastases. J Clin Oncol 24: 2065-2072, 2006.
7. Rubbia-Brandt L, Audard V, Sartoretti P, Roth AD, Brezault C, Le Charpentier M, Dousset B, Morel P, Soubrane O, Chaussade S, et al: Severe hepatic sinusoidal obstruction associated with oxaliplatin-based chemotherapy in patients with metastatic colorectal cancer. Ann Oncol 15: 460-466, 2004.

8. Fernandez FG, Ritter J, Goodwin JW, Linehan DC, Hawkins WG and Strasberg SM: Effect of steatohepatitis associated with irinotecan or oxaliplatin pretreatment on resectability of hepatic colorectal metastases. J Am Coll Surg 200: 845-853, 2005.

9. Zorzi D, Laurent A, Pawlik TM, Lauwers GY, Vauthey JN and Abdalla EK: Chemotherapy-associated hepatotoxicity and surgery for colorectal liver metastases. Br J Surg 94: 274-286, 2007.

10. Aloia T, Sebagh M, Plasse M, Karam V, Lévi F, Giacchetti S, Azoulay D, Bismuth H, Castaing D and Adam R: Liver histology and surgical outcomes after preoperative chemotherapy with fluorouracil plus oxaliplatin in colorectal cancer liver metastases. J Clin Oncol 24: 4983-4990, 2006.

11. Kleiner DE, Brunt EM, Van Natta M, Behling C, Contos MJ, Cummings OW, Ferrell LD, Liu YC, Torbenson MS, Unalp-Arida A, et al: Design and validation of a histological scoring system for nonalcoholic fatty liver disease. Hepatology 41 : 1313-1321, 2005

12. Benoist S, Salabert AS, Penna C, Karoui M, Julié C, Rougier P and Nordlinger B: Portal triad clamping (TC) or hepatic vascular exclusion (VE) for major liver resection after prolonged neoadjuvant chemotherapy? A case-matched study in 60 patients. Surgery 140: 396-403, 2006

13. Robinson SM, Wilson CH, Burt AD, Manas DM and White SA: Chemotherapy-associated liver injury in patients with colorectal liver metastases: A systematic review and meta-analysis. Ann Surg Oncol 19: 4287-4299, 2012.

14. Tamandl D, Klinger M, Eipeldauer S, Herberger B, Kaczirek K, Gruenberger B and Gruenberger T: Sinusoidal obstruction syndrome impairs long-term outcome of colorectal liver metastases treated with resection after neoadjuvant chemotherapy. Ann Surg Oncol 18: 421-430, 2011.

15. Karoui M, Penna C, Amin-Hashem M, Mitry E, Benoist S, Franc B, Rougier P and Nordlinger B: Influence of preoperative chemotherapy on the risk of major hepatectomy for colorectal liver metastases. Ann Surg 243: 1-7, 2006.

16. Soubrane O, Brouquet A, Zalinski S, Terris B, Brézault C, Mallet V, Goldwasser F and Scatton O: Predicting high grade lesions of sinusoidal obstruction syndrome related to oxaliplatin-based chemotherapy for colorectal liver metastases: Correlation with post-hepatectomy outcome. Ann Surg 251: 454-460, 2010

17. Brouquet A, Benoist S, Julie C, Penna C, Beauchet A, Rougier P and Nordlinger B: Risk factors for chemotherapy-associated liver injuries: A multivariate analysis of a group of 146 patients with colorectal metastases. Surgery 145: 362-371, 2009.

18. Goldberg RM, Tabah-Fisch I, Bleiberg H, de Gramont A, Tournigand C, Andre T, Rothenberg ML, Green E and Sargent DJ: Pooled analysis of safety and efficacy of oxaliplatin plus fluorouracil/leucovorin administered bimonthly in elderly patients with colorectal cancer. J Clin Oncol 24: 4085-4091, 2006. 